\title{
The nitric oxide-donor molsidomine modulates the innate inflammatory response in a mouse model of muscular dystrophy
}

\author{
Paola Zordan ${ }^{\text {a }}$, Clara Sciorati a , Lara Campana ${ }^{\text {, }}$ Lucia Cottone ${ }^{\text {a }}$, Emilio Clementi ${ }^{\text {b,c,1 }}$, \\ Patrizia-Rovere Querini ${ }^{\mathrm{a}, 1}$, Silvia Brunelli ${ }^{\mathrm{a}, \mathrm{d}, *, 1}$ \\ a Division of Regenerative Medicine, Stem Cells and Gene Therapy, San Raffaele Scientific Institute, Milano, Italy \\ b Scientific Institute, IRCCS Eugenio Medea, Bosisio Parini, Lecco, Italy \\ ${ }^{\mathrm{c}}$ Unit of Clinical Pharmacology, Consiglio Nazionale delle Ricerche, Institute of Neuroscience, Department of Biomedical and Clinical Sciences L. Sacco, \\ University Hospital "Luigi Sacco", Università di Milano, Milan, Italy \\ ${ }^{\mathrm{d}}$ Department of Health Sciences, Milano-Bicocca University, Milano, Italy
}

\section{A R T I C L E I N F O}

\section{Article history:}

Received 4 January 2013

Received in revised form

26 April 2013

Accepted 5 May 2013

Available online 23 May 2013

\section{Keywords:}

Macrophages

Molsidomine

Nitric oxide

Muscular dystrophy

$\alpha$-Sarcoglican

\begin{abstract}
A B S T R A C T
Inflammation plays a crucial role in muscle remodeling and repair after acute and chronic damage, in particular in muscular dystrophies, a heterogeneous group of genetic diseases leading to muscular degeneration. Defect of nitric oxide (NO) generation is a key pathogenic event in muscular dystrophies, thus NO donors have been explored as new therapeutics for this disease. We have investigated the immune-modulating effect of one of such drugs, molsidomine, able to slow the progression of muscular dystrophy in the $\alpha$-Sarcoglican-null mice, a model for the limb girdle muscular dystrophy 2D, sharing several hallmarks of muscle degeneration with other muscular dystrophies. $\alpha$-Sarcoglican-null mice were treated with molsidomine and drug effects on the inflammatory infiltrates and on muscle repair were assessed at selected time points. We found that molsidomine treatment modulates effectively the characteristics of the inflammatory infiltrate within dystrophic muscles, enhancing its healing function. Initially molsidomine amplified macrophage recruitment, promoting a more efficient clearance of cell debris and effective tissue regeneration. At a later stage molsidomine decreased significantly the extent of the inflammatory infiltrate, whose persistence exacerbates muscle damage: most of the remaining macrophages displayed characteristics of the transitional population, associated with reduced fibrosis and increased preservation of the muscle tissue. The dual action of molsidomine, the already known NO donation and the immunomodulatory function we now identified, suggests that it has a unique potential in tissue healing during chronic muscle damage. This, alongside its already approved use in human, makes molsidomine a drug with a significant therapeutic potential in muscular dystrophies.
\end{abstract}

(c) 2013 Elsevier B.V. All rights reserved.

\section{Introduction}

Muscular dystrophies are a group of muscle degenerative diseases of genetic origin, characterized by progressive skeletal muscle weakness, defects in muscle proteins and fiber necrosis, leading to the progressive substitution of fibers with connective and adipose tissue (Emery, 2002).

The progression of the disease is also influenced by the extensive inflammatory response that persists in the muscle (Brunelli and Rovere-Querini, 2008). Leukocytes and in particular macrophages dominate the inflammatory response in muscle that follows acute or chronic damage (Nguyen and Tidball, 2003; Tidball, 2005; Villalta et al., 2011b). Macrophages are rich sources

\footnotetext{
* Correspondence to: Division of Regenerative Medicine, Stem Cells and Gene Therapy, San Raffaele Scientific Institute, Via Olgettina 58, 20132 Milano, Italy.

E-mail address: brunelli.silvia@hsr.it (S. Brunelli).

${ }^{1}$ Equally contributed.
}

of growth factors and cytokines, as well as of potentially tissue damaging species, like free radicals (Brunelli and Rovere-Querini, 2008; Tidball and Villalta, 2010), and have been described to contribute not only to the worsening and progression of muscular dystrophies (Tidball, 2005; Wehling et al., 2001), but also to stem cell recruitment, differentiation and therefore muscle repair (Arnold et al., 2007; Bosurgi et al., 2012; Lesault et al., 2012; Villalta et al., 2011a). To these different outcomes the remarkable plasticity of these cells that change their physiology in response to environmental cues (Gordon and Martinez, 2010). As a consequence, macrophages with distinct functions are defined as "classically activated" or "inflammatory" (expressing markers such as CD86) or "alternatively activated" (expressing the mannose receptor CD206), and these latter comprise two main subpopulations, the "wound-healing" (mainly $\mathrm{CD} 206^{+} \mathrm{CD} 163^{+}$) and the "reg-

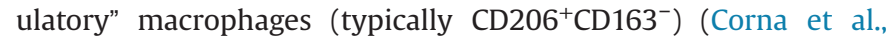
2010; Mantovani et al., 2013; Martinez et al., 2006; Mosser and Edwards, 2008; Tidball, 2005). 
Several studies had shown that the pathophysiology of muscular dystrophies correlates with an altered synthesis of nitric oxide (NO) (De Palma and Clementi, 2012). In patients and animal models of muscular dystrophies, the splice variant of neuronal nitric oxide synthase (nNOS) is absent from the sarcolemma, and relocated to the cytosol, with total muscle NOS activity being thus reduced (Brenman et al., 1995; Chang et al., 1996). The restoration of NO generation by transgenic expression of nNOS ameliorates the dystrophic phenotype (Wehling et al., 2001; Wehling-Henricks and Tidball, 2011). NO has been shown to enhance repair of the damaged muscle via actions on survival, activation and differentiation of satellite cells (Anderson, 2000; Buono et al., 2012; Filippin et al., 2009).

These results prompted investigation of NO donors as therapeutics; however, they failed to yield persistent beneficial effect in terms of functional muscle recovery (Marques et al., 2005; Voisin et al., 2005; Wang et al., 2009). We found that for NO release to have significant and persistent therapeutic effects it has to be combined with non steroidal anti-inflammatory (NSAID) activity; the combination of these pharmacological activities resulted in an increased muscle progenitor differentiation, survival and selfrenewal and quenching of inflammation all contributing to effective muscle repair (Brunelli et al., 2007; Sciorati et al., 2010; Sciorati et al., 2011).

Recently, however, we found that a NO donor, molsidomine, is able to slow disease progression of muscular dystrophies in the absence of a NSAID, and to restore the functional capacity of damaged muscle, significantly enhancing spontaneous and forced motor activities (Buono et al., 2012). In view of the polytherapeutic regimes of dystrophic patients, the use of an effective NO donor without a NSAID activity appears a possible advantage. Part of the beneficial effect of molsidomine may be explained by its capability to boost the self-renewal ability of satellite cells thus preventing the exhaustion of the satellite cells pool (Buono et al., 2012). This effect however is unlikely to explain in full the therapeutic efficacy of molsidomine in such a complex disease as muscular dystrophy.

We investigated whether and how, in addition to this specific effect on myogenic stem cell self-renewal and differentiation, NO released by molsidomine orchestrated inflammation directing it into a "repair mode", further contributing to tissue remodeling in chronic muscle damage. We found in the $\alpha$-Sarcoglican-null ( $\alpha-S G)$ mice, a model for Limb Girdle muscular dystrophy 2D endowed with a severe dystrophic phenotype that molsidomine has a unique ability to regulate immune responses in dystrophic muscle enhancing their healing function.

\section{Materials and methods}

\subsection{Animals and treatments}

$\alpha$-SG mice were housed in the pathogen-free facility at the San Raffaele Scientific Institute (Milano-Italy), and treated in accordance with the European Community guidelines, and with the approval of the Institutional Ethical Committee. Mice (5 animals/ group) were treated with $3 \mathrm{mg} / \mathrm{kg}$ of (1-ethoxy-N-(3-morpholino5-oxadiazol-3-iumyl)methanimidate (molsidomine) administered daily into the diet (Mucedola, Milano, Italy) or with the same food without drug (control group) starting at 1 month of age for up to 5 months. The dose is higher than the one commonly used in chronic therapies in humans ( $8-16 \mathrm{mg} / \mathrm{day})$, where it is used in a different therapeutic setting, i.e. heart diseases (Baudry, 1982; Messin et al., 2006). The diet was added daily and its consumption, a measure of drug intake, was assessed by weighting it daily before the next diet administration. After 1 and 4 months of treatment, mice were sacrificed for histological analyses, cytokine expression analysis and FACS analysis.

\subsection{Histology on tissue sections}

Control and treated $\alpha$-SG mice were sacrificed by cervical dislocation, and TA muscles were dissected and immediately frozen in liquid $\mathrm{N}_{2}$-cooled isopentane. For histological analysis, serial muscle sections were obtained and stained in hematoxylin and eosin (H\&E) following standard procedures. Necrotic cells were identified by hypereosinophilia, thinning and waviness, and presence of many nuclei while regenerating fibers were distinguished based on the central localization of their nuclei and dimension of cross areas. Masson trichrome staining was performed in serial muscle sections following manufacturer's procedures (Bio Optica, Milan Italy) to evaluate fibrosis in the tissue. Twenty random images for each muscle were taken at $20 \times$ magnification with a Nikon Eclipse E600 microscope (Nikon Instruments Europe).

\subsection{Immunohistochemical and immunofluorescence analysis}

Immunohistochemical and immunofluorescence analyses were performed on frozen tibialis anterior muscles (TA) sections from control and treated $\alpha$-SG mice using the following antibodies: CD45 (Biotin mouse anti-mouse CD45.2, BD Pharmigen, 1:50); CD68 (AbD serotec, 1:150), CD 206 (AbD serotec, 1:100), CD163 (Santa Cruz Biotechnology, 1:100), CD86 (BD Pharmigen, 1:100), Ly6G (Biolegend,1:100; clone 1A8).

Sections of TA muscles were air-dried for $30 \mathrm{~min}$ and fixed in acetone at $-20{ }^{\circ} \mathrm{C}$ or $4 \%$ paraformaldehyde at room temperature for $10 \mathrm{~min}$. For IHC staining, sections were blocked first with a blocking kit (streptavidin/biotin blocking kit, Vector Laboratories). IHC and IF sections were both blocked for $1 \mathrm{~h}$ with $5 \%$ bovine serum albumin (BSA) and $0.1 \%$ Triton diluted in PBS $1 \times$. Sections were then incubated with antibodies overnight at $4{ }^{\circ} \mathrm{C}$. Sections were washed with PBS and then incubated with biotin-conjugated secondary antibodies (Vector Laboratories,1:200, for immunohistochemical analysis) or with appropriated secondary antibodies (Alexafluor, 1:500) for $1 \mathrm{~h}$ at room temperature. When biotinconjugated secondary antibodies were present, sections were subsequently washed with PBS and incubated for 30 min with streptavidin-HRP (BD Pharmigen, 1:200). Staining was visualized as a brown reaction product with peroxidase substrate (Vector Novared).

Nuclei were revealed by counterstaining with hematoxylin or Hoechst.

For each experiments 20 random images for each muscle were taken at $20 \times$ or $40 \times$ magnification using a Nikon Eclipse E600 microscope (Nikon Instruments Europe) with a Digital camera DXm1200 (Nikon, Nikon Instruments Europe) and analyzed using a digitized imaging systems (ImageJ $1.38 ¥$ National Institute of Health) and Adobe Photoshop CS4 program.

\subsection{Real-time polymerase chain reaction}

RNA was extracted form TA muscle of control and treated $\alpha$-SG mice using Trizol, and $1 \mu \mathrm{g}$ of RNA per sample was reverse transcribed into cDNA using the High Capacity Reverse Transcription kit (Applied Biosistem) according to the manufacturer's instructions. Quantitative PCR was performed using SYBRgreen PCR Master Mix (Applied Biosystems, Life Technologies Europe). Results were quantified using ABI7900 machine (Applied Biosystems). The level of RNA was normalized to the corresponding level of GAPDH messenger RNA (mRNA) for total muscle lysates. Sequences of primers (Primm, Milan, Italy) used in quantitative 
real-time PCR are as follows ( 5 ' to 3' sequence): igf1 (Fw: GTG TGG ACC GAG GGG CTT TTA CTT C; Rv: GCT TCA GTG GGG CAC AGT ACA TCT C); tnf $\alpha$ (Fw: TCC CAG GTT CTC TTC AAG GGA; Rv: GGT GAG GAG CAC GTA GTC GG); il10 (Fw: ATT TGA ATT CCC TGG GTG AGA AG; Rv: CAC AGG GGA GAA ATC GAT GAC A); il1 $\beta$ (Fw: GCA ACT GTT CCT GAA CTC AAC T; Rv: ATC TTT TGG GGT CCG TCA ACT); gapdh (Fw: TCC ACT CAT GGC AAATTC AA; Rv: TTT GAT GTT AGT GGG GTC TCG).

\subsection{Flow cytometry analysis of immune cells}

For the analysis of composition of immune cell lineages by polychromatic flow cytometry, suspension of single cells was obtained from TA muscles isolated from control and treated $\alpha$-SG mice by enzymatic digestion. Approximately $1-5 \times 10^{5}$ cells were first incubated $30 \mathrm{~min}$ on ice with Rat Anti-Mouse Fc $\gamma$ III/II Receptor $(2 \mu \mathrm{g} / \mathrm{ml}$ of $2.4 \mathrm{G} 2$, BD Pharmingen) to block nonspecific binding and with LIVE/DEAD ${ }^{\circledR}$ Fixable Aqua Dead Cell Stain Kit (1:500, Invitrogen) to exclude dead cells and debris. After washing, a 30 min incubation was performed in PBS containing 5\% FCS and $0.1 \mathrm{mM}$ EDTA on ice using appropriate combinations of the following monoclonal antibodies: Alexa 700 anti-CD45 for leukocytes gating (BD Biosciences, clone 30-F11, dilution 1:65), PE-CY7 anti-CD3 for T lymphocytes (BD Biosciences, clone 145-2C11, dilution 1:65), FITC anti-Ly6G for neutrophils (Biolegend, clone1A8, dilution 1:200), FITC anti-CD19 for B lymphocytes (BD Biosciences, clone 1D3, dilution 1:200), PERCP anti-NK1.1 for natural killer cells (BD Biosciences, clone PK136, dilution 1:100), APC anti-CD11b (Biolegend, clone M1/70, dilution 1:125) and APCCY7 anti-F4/80 (Biolegend, clone BM8, dilution 1:50) for macrophages, APC-CY7 anti-CD11c for dendritic cells (BD Biosciences, clone HL3, dilution 1:100).

Cells were then washed once, incubated with Hoechst 33342 $(1 \mu \mathrm{g} / \mathrm{ml})$, washed once, fixed in $1 \%$ PFA for 20 min on ice, washed again, and stored at $4{ }^{\circ} \mathrm{C}$ until analysis that was done using an LSR Fortessa flow cytometer with Diva Software (BD Bioscience). Percentage of positive cells was evaluated with FlowJo Software (Tree Star, v. 9.4.4).

\subsection{Statistical analysis}

Results are expressed as the means \pm S.E.M. or median (plus $90 \%$ interval of confidence) according to their distribution based on results of the Kolmogorov-Smirnov normality test. For the parameters with a normal distribution, the ANOVA test was used, whereas the Mann and Whitney (Kruskal-Wallis test) test was used for parameters with non-normal distribution. A P-value of less than 0.05 was considered as statistically significant.

\section{Results}

To assess the effects of NO on inflammation in muscular dystrophy, we relied on the $\alpha$-SG mice, a model for Limb Girdle Muscular Dystrophy 2D, that has a severe dystrophic phenotype and is a good model to assess the long-term efficacy of drugs active on muscular dystrophies (Brunelli et al., 2007; Duclos et al., 1998).

1-month-old $\alpha$-SG mice were treated with the NO-releasing drug molsidomine for 1 or 4 months, a treatment schedule known to prevent the development of the dystrophic phenotype, both morphologically and functionally (Buono et al., 2012). Mice were then sacrificed and the extent and characteristics of the inflammatory infiltrate analyzed by multiparametric flow cytometry and immunohistochemistry.
H\&E staining of TA muscles from 1-month mice revealed the typical dystrophic phenotype, with no differences between control and molsidomine-treated animals (Fig. 1A). The tissue was characterized by large number of infiltrating cells (Fig. 1A) and regenerating myofibers. Immunohistochemistry analysis confirmed that infiltrating cells are $\mathrm{CD}^{4} 5^{+}$(Fig. 1B) and interestingly we detected a significantly more extensive inflammatory infiltrate in molsidomine-treated animals with respect to control mice (graph in Fig. 1B).

TA muscles of 5 months old $\alpha$-SG control mice were characterized by large areas of infiltrating mononuclear cells (Fig. 1C) and the tissue appeared more disorganized.

In 4-months molsidomine treated mice TA muscles were much more preserved in structure (Fig. 1C) and myofibers showed an increased cross section area with respect to controls. In support of the persistence of a better regeneration in muscles of molsidominetreated mice (Buono et al., 2012), the mRNA levels of Igf1, a master regulator of myogenesis, were significantly increased in treated $v s$. control muscles (Fig. 1D).

In treated mice, infiltrating cells were significantly less abundant (Fig. 1C) and immunohistochemistry analysis confirmed that $\mathrm{CD}_{4} 5^{+}$cells were significantly decreased in treated muscle $(49 \pm 6.8 \%$ with respect to controls, $P<0.005$ vs. control) (Fig. $1 \mathrm{E}$ and graph in Fig. 1E).

To identify and quantify the various leukocyte populations we performed a multiparametric flow cytometry analysis on $\mathrm{CD}$ $45^{+}$cells isolated from total muscle after enzymatic digestion. At 1 month the distribution of the leukocyte populations did not differ between control and molsidomine-treated mice, with a substantial infiltration by macrophages $\left(\mathrm{CD} 11 \mathrm{~b}^{+} \mathrm{F} 4 / 80^{+}\right)$, followed by $\mathrm{T}$ cells $\left(\mathrm{CD}^{+}\right)$, neutrophils $\left(\mathrm{CD} 11 \mathrm{~b}^{+} \mathrm{Ly}_{6 \mathrm{G}^{+}}\right)$and dendritic cells $\left(\mathrm{CD} 11 \mathrm{c}^{+} \mathrm{CD} 11 \mathrm{~b}^{+}\right.$) (Fig. 2A). Immunohistochemistry confirmed that the increase of $\mathrm{CD} 45^{+}$cells in the muscle we saw (Fig. 1) corresponded to an increased number of $\mathrm{CD}^{+} 8^{+}$macrophages (Fig. 2B). Consistently in 1-month molsidomine-treated muscles, the inflammatory cytokines IL1 $\beta$, TNF $\alpha$ and IL10 were more abundantly expressed than in controls (Supplementary Fig. S1).

FACS analysis of the cellular composition after 4-month of treatment revealed that molsidomine reduced the percentage of macrophages and neutrophils in the $\mathrm{CD} 45^{+}$population (Fig. 2C). This reduction was confirmed by counting the number of $\mathrm{CD}^{+} 8^{+}$ (macrophages) or $\mathrm{Ly}_{6 \mathrm{G}}^{+}$cells (neutrophils) in muscle sections immunostained with the specific antibodies (Fig. 2D E).

We then investigated further the phenotype of infiltrating macrophages by immunohistochemistry and immunofluorescence. In particular we quantified the number of $\mathrm{CD}^{+} 6^{+}$macrophages and of $\mathrm{CD}_{163}{ }^{+} \mathrm{CD} 206^{+}$or $\mathrm{CD} 163^{-} \mathrm{CD} 206^{+}$(alternatively activated) macrophages (Fig. $3 \mathrm{~A}$ and $\mathrm{B}$ ). At all times analyzed we confirmed that all $\mathrm{CD} 163^{+}$cells were also CD206 ${ }^{+}$. After 1 month, control and molsidomine-treated mice displayed similar distributions of the population of macrophages with a relative abundance

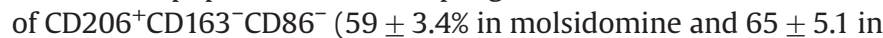
controls) and $\mathrm{CD} 206^{+} \mathrm{CD} 163^{+} \mathrm{CD}^{-} 6^{-}$cells $(22 \pm 2.4 \%$ in molsidomine and $16 \pm 3.9 \%$ in controls) (Fig. $3 \mathrm{~A}$ and $\mathrm{A}^{\prime}$ ).

The picture however was significantly different at the 4 months time-window. In muscles of $\alpha$-SG control mice the number of pro-

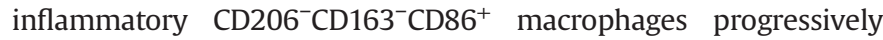
increases with time reaching $24 \pm 3.2 \%$ of the whole population in untreated animals (graph in Fig. 3B). Molsidomine prevented the

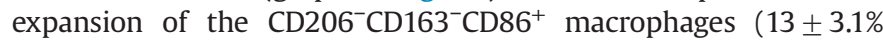
$P<0.05$ vs. control) (Fig. 3B and $\mathrm{B}^{\prime}$, graph in Fig. 3B), and favored the appearance of a transitional population expressing CD2$06^{+} \mathrm{CD} 163^{+} \mathrm{CD}^{+} 6^{+}(47 \pm 4.7 \%$ in molsidomine vs. $13 \pm 2.8 \%$ in controls $P<0.001$ vs. control) (Fig. 3B).

The general decrease in the number of macrophages and the modulation of their relative proportions was accompanied by a 
A

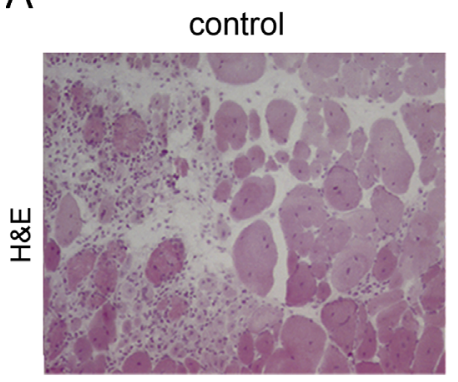

B

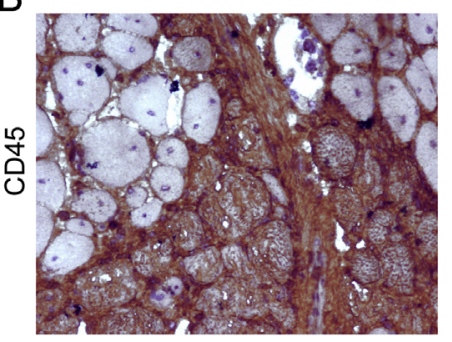

1 month
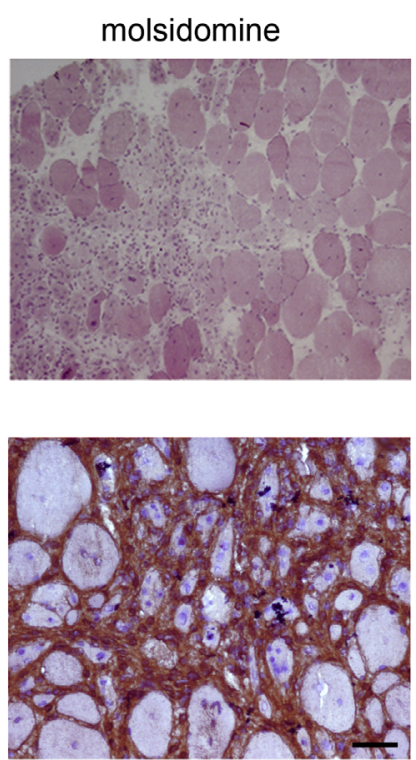

4 months

C
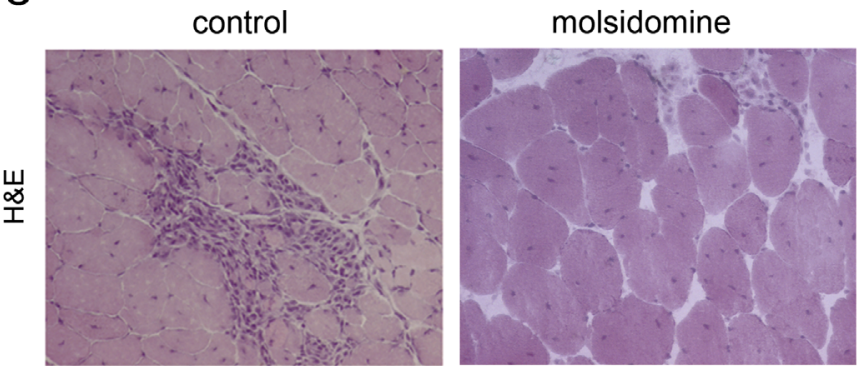

E
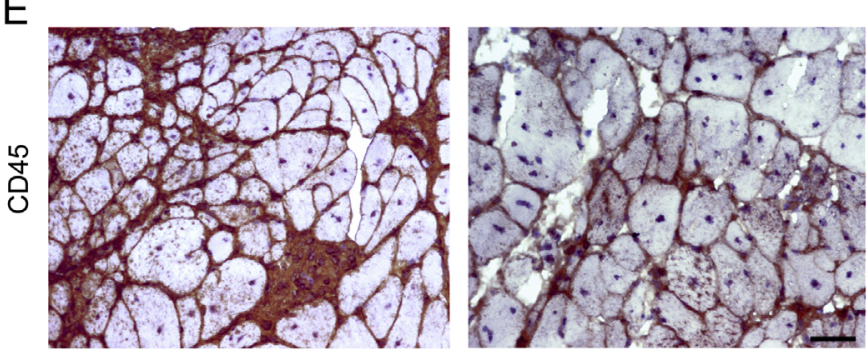

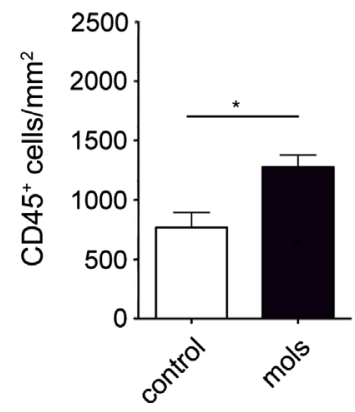

$\mathrm{D}$
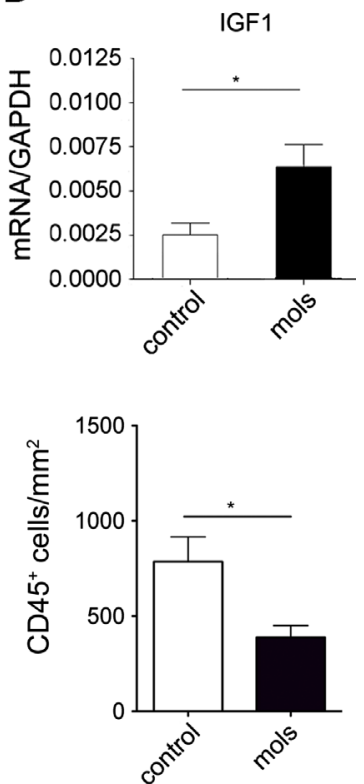

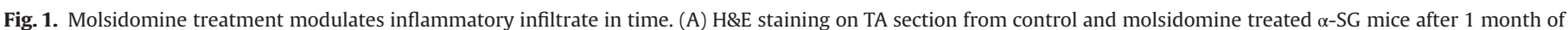

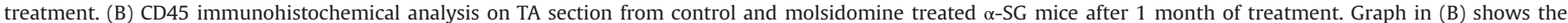

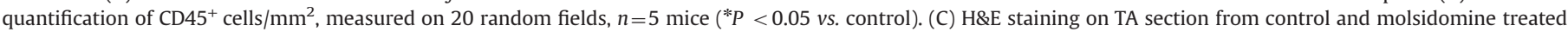

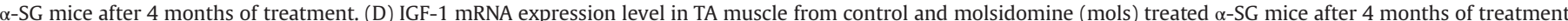

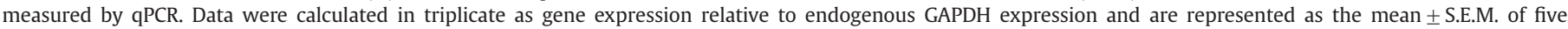

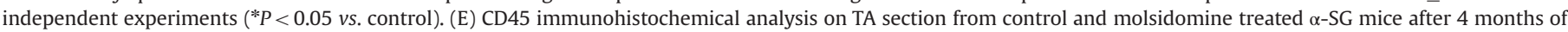
treatment. Graph in E shows the quantification of $\mathrm{CD} 45^{+}$cells $/ \mathrm{mm}^{2}$, measured on 20 random fields, $n=5$ mice $\left({ }^{*} P<0.05 v s\right.$. control). Scale bar: $50 \mu \mathrm{m}$.

decrease in the fibrosis in TA of 4 months molsidomine-treated mice with respect to control animals, in which muscle tissue was partially substituted by fibrotic scars (Fig. 4).

\section{Discussion}

In this study we show that treatment with molsidomine, a NO donor approved for use in humans, modulates effectively the characteristics of the inflammatory infiltrate within dystrophic muscles. We observed distinct effects depending on the phase of the disease. Initially, the treatment contributed to more efficient macrophage recruitment to the dystrophic muscle. The phenotype of infiltrating macrophages was heterogeneous, and expression analysis showed that they express both inflammatory cytokines (IL1 $\beta$ and TNF $\alpha$ ) (Crisafulli et al., 2009) and those typically expressed by regulatory macrophages, such as IL10 (Villalta et al., 2011b). Molsidomine in the early phases of the disease appears to amplify macrophage recruitment, thus promoting a more efficient clearance of cell debris and possibly a more effective regeneration of the tissue (Tidball and Villalta, 2010). IL10 in particular, via expansion of alternatively activated macrophages, results in the local generation of other growth factors, including IGF1 (Bosurgi et al., 2012; Villalta et al., 2011b). TNF $\alpha$ promotes muscle regeneration by positively influencing the recruitment, proliferation and differentiation of myogenic precursors (Galvez 
A

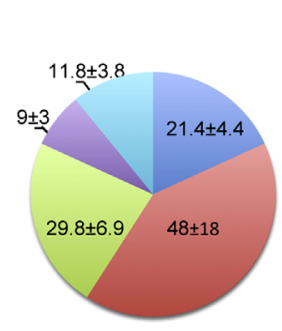

1 month

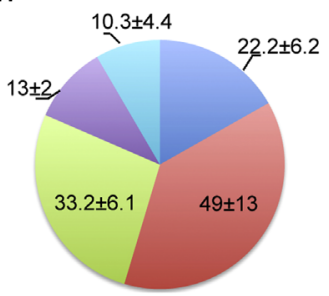

B
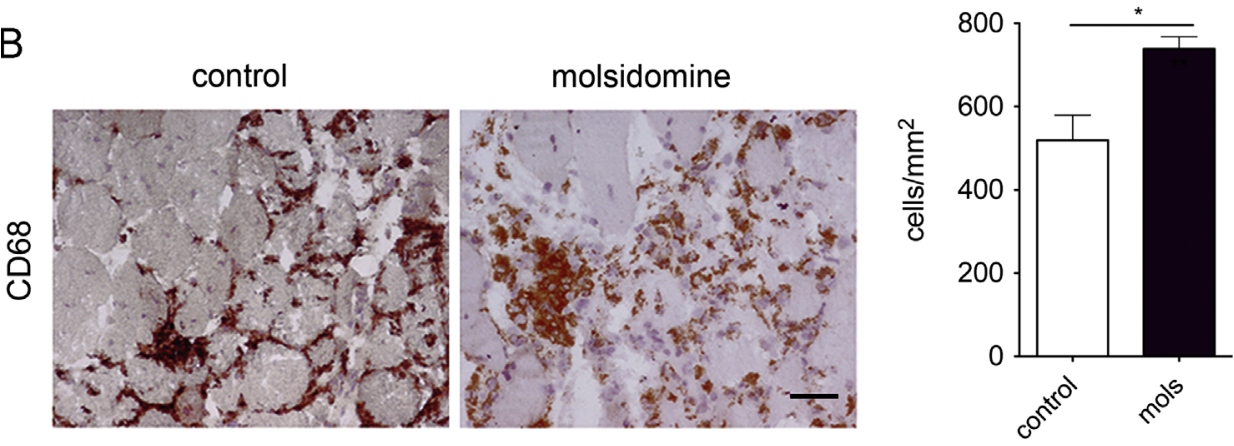

C

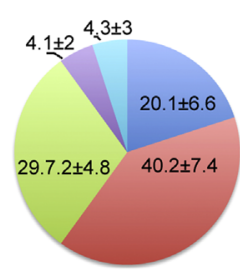

\section{4 months}

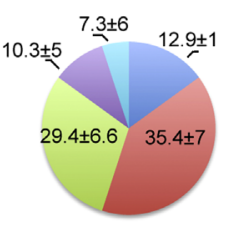

$\mathrm{D}$
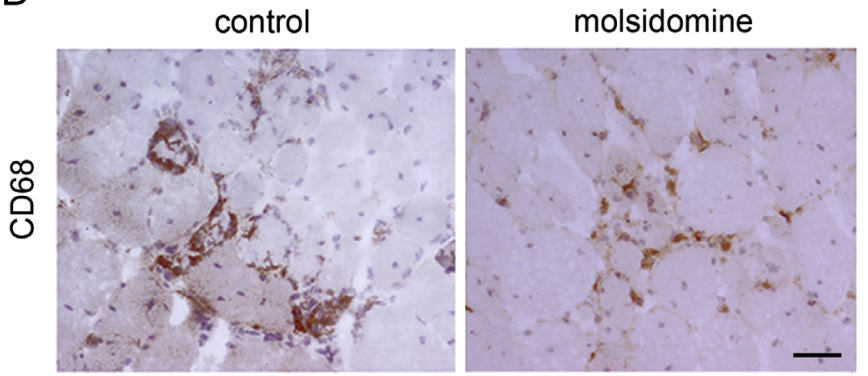

E
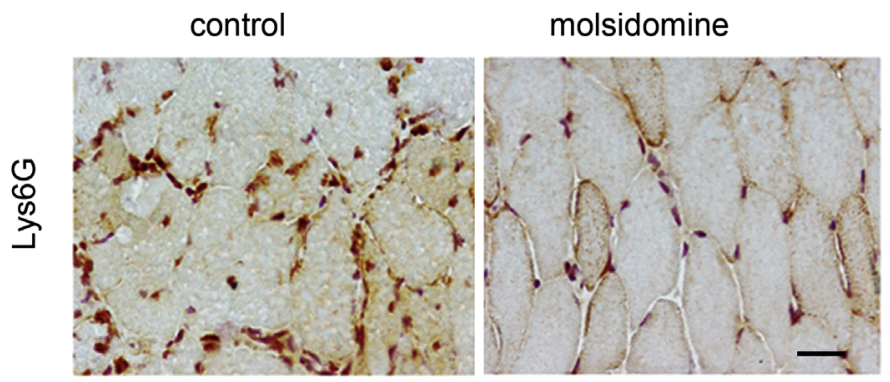

Macrophages

Tlymphocytes

Dendritic cells

other (NK+B cells)
Neutrophils

Neutrophils

Macrophages

-T lymphocytes

Dendritic cells

other (NK+B cells)
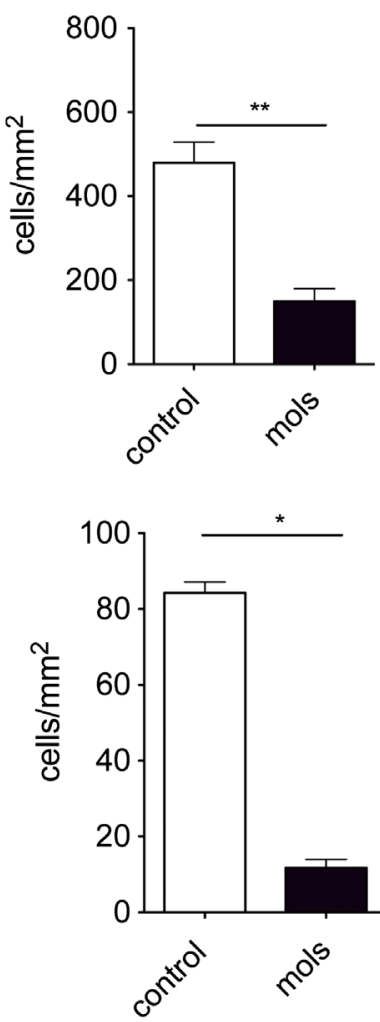

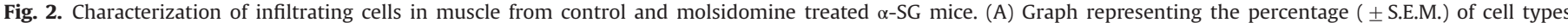

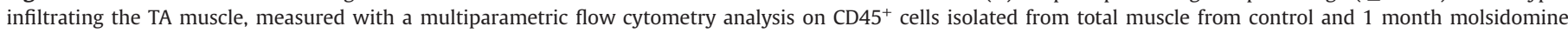

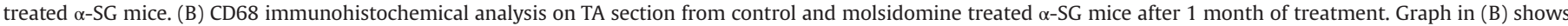

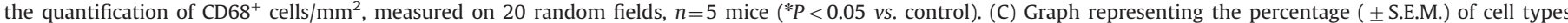

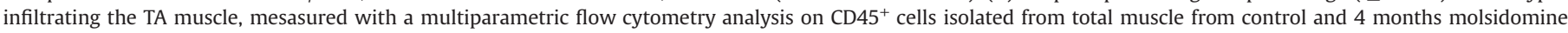

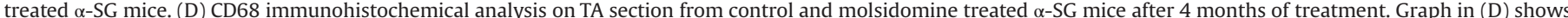

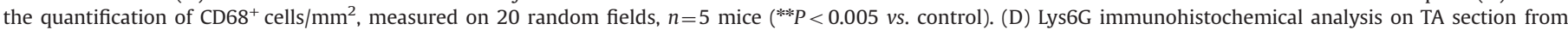

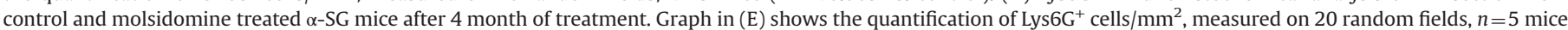
$\left({ }^{*} \mathrm{P}<0.05 v s\right.$. control). Scale bar: $50 \mu \mathrm{m}$. 

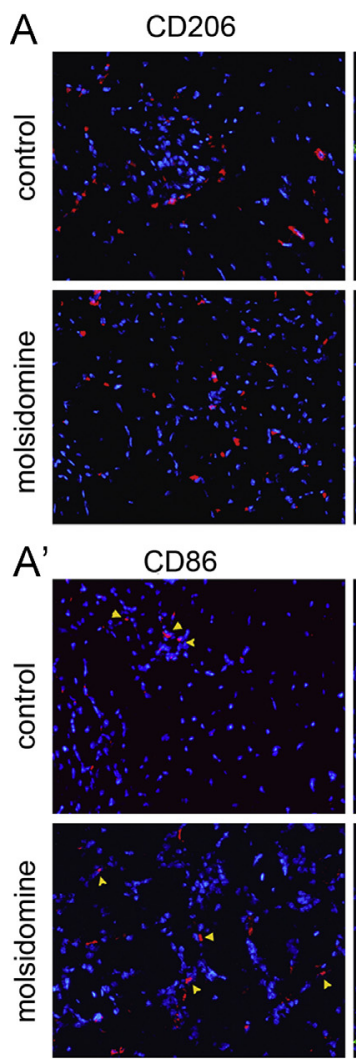

B
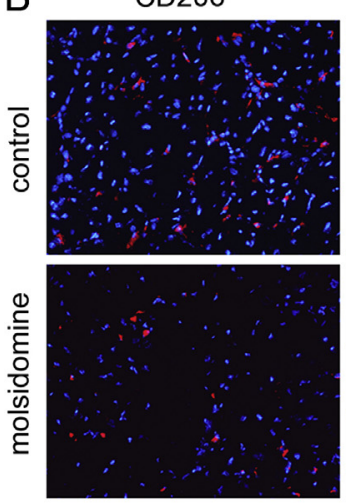

B'
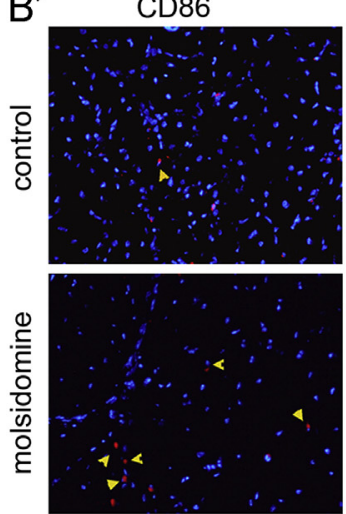

CD163

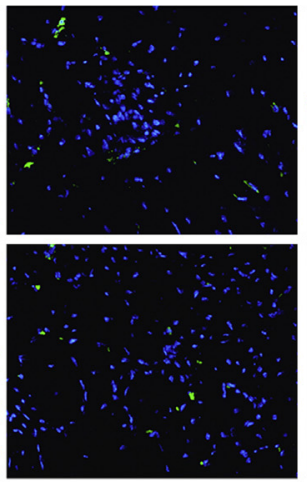

CD163
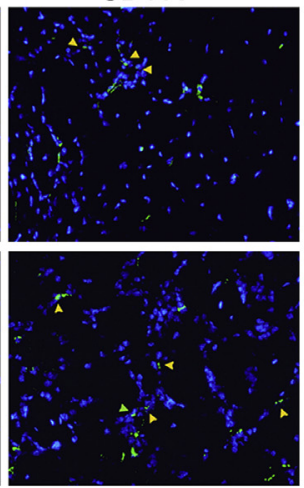

CD163
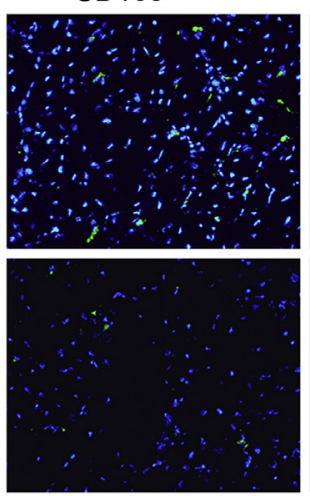

CD163
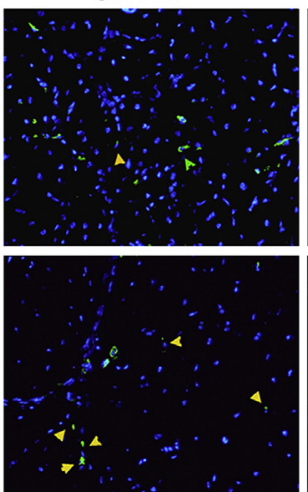

merge
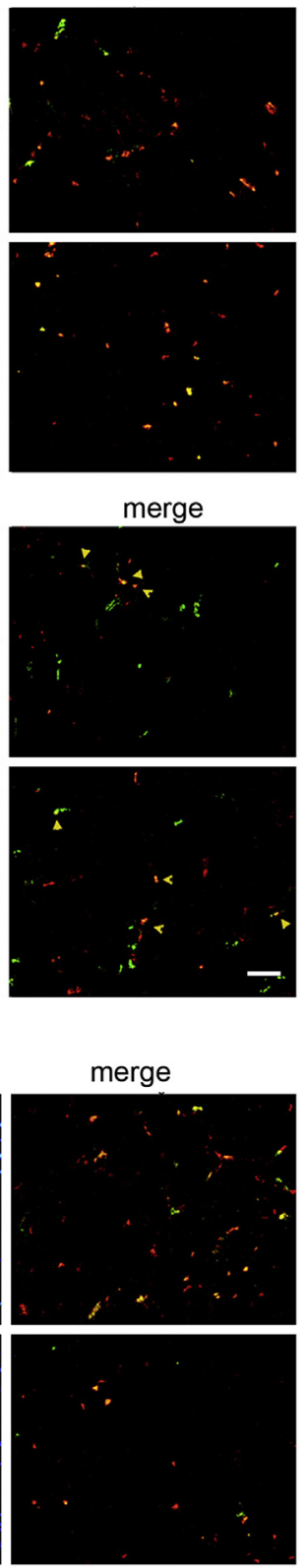

merge
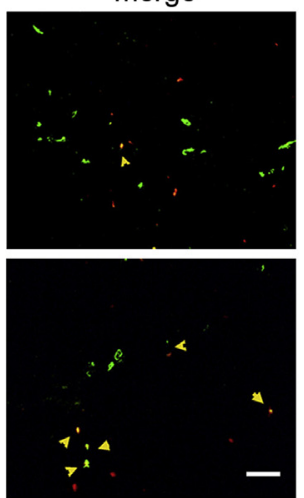

control

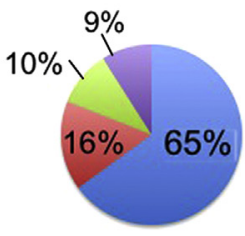

Molsidomine

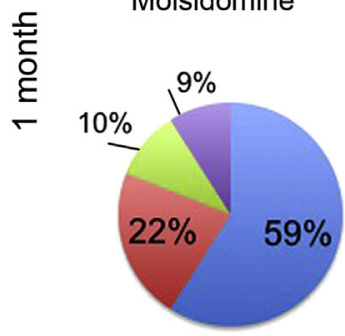

- CD206+CD163-CD86

= CD206 ${ }^{+} \mathrm{CD} 163^{+} \mathrm{CD} 86-$

- CD206-CD163-CD86 ${ }^{+}$

- $\mathrm{CD} 206^{+} \mathrm{CD} 163^{+} \mathrm{CD} 86^{+}$

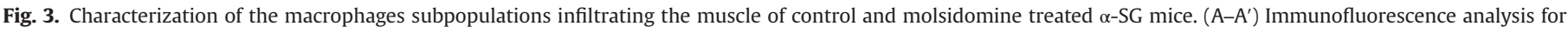

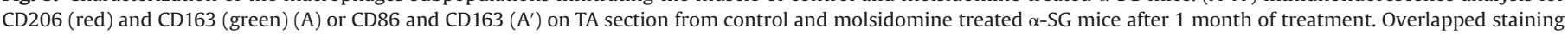

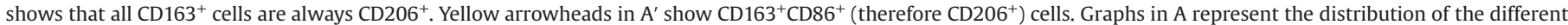

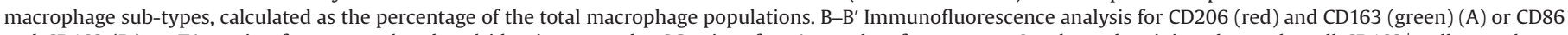

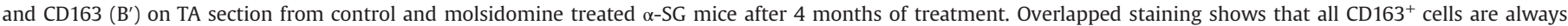

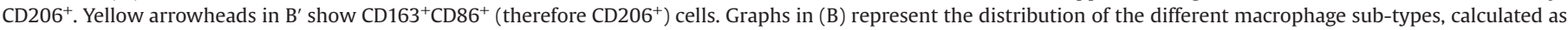

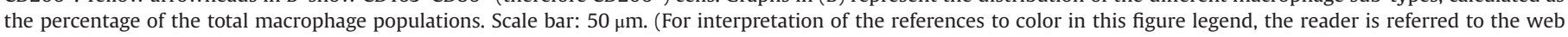
version of this article.) 

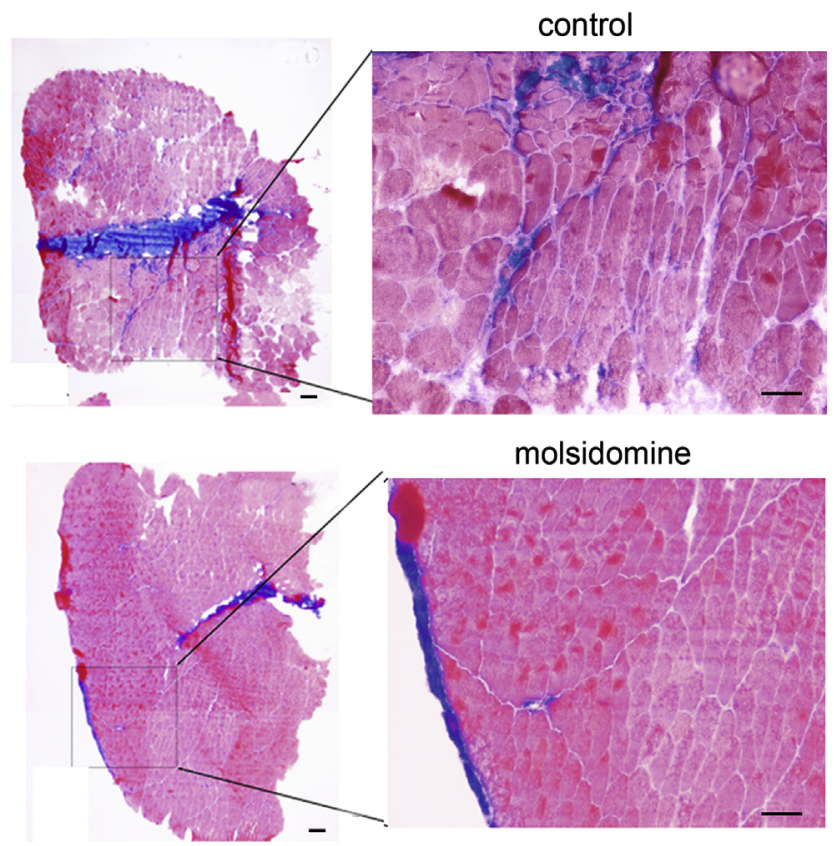

Fig. 4. Molsidomine treatment leads to a reduced fibrotic scar. Representative tricromic staining of TA section from control and molsidomine treated $\alpha$-SG mice after 4 months of treatment. Blue staining represents area of fibrosis. Scale bar: left $(4 \times)=100 \mu \mathrm{m}$; right $(40 \times)=20 \mu \mathrm{m}$. (For interpretation of the references to color in this figure legend, the reader is referred to the web version of this article.)

et al., 2006; Tidball and Villalta, 2010), acting at concentrations and/or on pathways different from those that prompt muscle wasting (Coletti et al., 2005; Sciorati et al., 2009).

The increase in the extent of macrophages infiltration at the onset of the chronic muscle injury is in keeping with the protective effects on myofibers observed at later stages. Moreover, after 4 months of treatment, molsidomine showed additional effects on inflammation that appear of therapeutic benefit. The drug decreased significantly the extent of the inflammatory infiltrate, with reduced numbers of neutrophils and of classically activated macrophages that, on the contrary, remained abundant in control dystrophic muscles. We can speculate that the persistence of these inflammatory populations in the untreated mice might depend on the limited efficacy of the clearance of cell remnants and in turn contribute to amplify the muscle damage associated to the genetic defect, thus contributing to accelerate muscle wasting (Hodgetts et al., 2006; Tidball and Villalta, 2010; Villalta et al., 2011a).

Interestingly after 4 months of molsidomine administration, most macrophages expressed both markers that are conventionally associated to classically and to alternatively activated macrophages $\left(\mathrm{CD}_{206}{ }^{+} \mathrm{CD} 163^{+} \mathrm{CD} 86^{+}\right)$. Macrophages co-expressing the markers of both macrophage populations might represent a transitional population, which maintain the ability to sustain the proliferation and differentiation of myogenic precursors (Mosser and Edwards, 2008; Tidball and Villalta, 2010). Accordingly, the up-regulation of the expression of IGF1 suggests that in this phase the remaining macrophages act in maintaining the pool of myogenic precursors and promoting their survival and differentiation (Bosurgi et al., 2012).

NO action in inflammation and immune responses has been intensively investigated and found to be complex and difficult to predict (Bogdan, 2001; Tripathi et al., 2007). For example inflammatory cell infiltration is reduced in mice deficient of the inducible form of NO synthase (iNOS) (Hickey, 2001). iNOS-derived NO, however, may also regulate the response to injury by reducing the extent of leukocyte infiltration, in particular neutrophils (McCafferty et al., 1997) and establish an effective homeostatic inflammatory response of the skeletal muscle to injury (Rigamonti et al., 2013). In a similar way, eNOS and nNOS derived-NO have been described to have different effects on inflammation and immune responses in different tissues and pathological conditions (Nagy et al., 2007; Wahl et al., 2003) (Wehling et al., 2001).

Thus the action of the NO depends significantly on the concentration and time-course of release; in particular the effect of NO released by NO-donating molecules is highly dependent on the pharmacological properties of its donating moiety; the NO donors have thus different effects on leukocyte recruitment and infiltration and on muscle regeneration depending on the pharmacokinetics of NO release (Dendorfer, 1996; Fung, 1993). The pharmacological properties of molsidomine may also contribute to explain the higher efficacy of this drug with respect to other NOdonating or NO-generating drugs investigated in the past as therapeutic approaches to muscular dystrophy, i.e. the NOS substrate L-arginine and the NO donor isosorbide dinitrate (Barton et al., 2005; Hnia et al., 2008; Marques et al., 2005; Sciorati et al., 2010; Voisin et al., 2005). The release of NO from molsidomine has a slower onset and is more prolonged than with isosorbide dinitrate (Agvald et al., 1999) and, at variance with isosorbide dinitrate, it occurs independently of interactions with thiolcontaining compounds (Noack and Feelisch, 1989). In addition it does not require active NOS, which is absent in the mdx mouse sarcolemma (Breeman et al., 1995) as instead L-arginine. To the enhanced effect of molsidomine the unique ability of molsidomine among NO-donors to stimulate the self-renewal of muscle myogenic precursor cells may also contribute (Buono et al., 2012).

The possibility to modulate finely the inflammatory response is of pivotal importance in chronic degenerative diseases of the skeletal muscle, in which a general non-specific anti-inflammatory activity could be more detrimental than beneficial. It could indeed limit the "noxious" actions of inflammatory cells that exacerbate the damage. However, it could also in parallel deprive the tissue of all signals provided by infiltrating leukocytes that appear to be more and more critical for the effective mobilization of myogenic stem cells, survival and differentiation (Bosurgi et al., 2012; Lesault et al., 2012). In contrast a pharmacological treatment able to promote the initial recruitment of leukocytes at sites of muscle injury and at later time points to quench the associated inflammatory response would be critical for efficient muscle repair. Endogenous NO has been shown to regulate inflammation in the dystrophic muscle in such a way that it contributes, alongside specific direct effect of NO on muscle (De Palma and Clementi, 2012), to its regeneration after damage (Rigamonti et al. 2013). The identification of a drug, molsidomine, that is able to release NO in such a way that it promotes a correct pro-inflammatory mode in muscular dystrophy, stimulating initially macrophage recruitment and then the shift toward a pro-regenerative mode even in the absence of any conventional anti-inflammatory component (NSAID or other), is thus extremely important in therapeutic perspective as it interconnects direct effects of NO on muscle with indirect effects via inflammation.

More studies will be required to finely tune the administration protocol in particular the timing and duration of the treatment; these studies should take into consideration also the early action on the developing myogenic precursors and earlier phases of inflammation. Still the combined effects of molsidomine, together with safety profile and use approval on humans, suggest that molsidomine is a valuable agent to be used in the development of new therapeutic strategies for muscular dystrophy.

\section{Acknowledgments}

This work was supported by the European Community framework programme FP7/2007-2013 under grant agreement nos. 
241440 (ENDOSTEM) (to S.B., P.Q.-R. and E.C.) and 223098 (OPTISTEM) (to S.B. and E.C.), the Italian Ministry of Health RC 2013 (to E. C.), Associazione Italiana Ricerca sul Cancro (AIRC IG11362, to E.C.), the Italian Ministry of Health (Fondo per gli Investimenti della Ricerca di Base-IDEAS to P.Q.-R.), and the Association Francaise contre les Myopathies (Grant 15440 to S.B. and P.Q.-R.).

\section{Appendix A. Supporting information}

Supplementary data associated with this article can be found in the online version at http://dx.doi.org/10.1016/j.ejphar.2013.05.007.

\section{References}

Agvald, P., Adding, L.C., Gustafsson, L.E., Persson, M.G., 1999. Nitric oxide generation, tachyphylaxis and cross-tachyphylaxis from nitrovasodilators in vivo. Eur. J. Pharmacol. 385, 137-145.

Anderson, J.E., 2000. A role for nitric oxide in muscle repair: nitric oxide-mediated activation of muscle satellite cells. Mol. Biol. Cell 11, 1859-1874.

Arnold, L., Henry, A., Poron, F., Baba-Amer, Y., van Rooijen, N., Plonquet, A., Gherardi, R.K. Chazaud, B., 2007. Inflammatory monocytes recruited after skeletal muscle injury switch into antiinflammatory macrophages to support myogenesis. J. Exp. Med. 204 1057-1069.

Barton, E.R., Morris, L., Kawana, M., Bish, L.T., Toursel, T., 2005. Systemic administration of L-arginine benefits mdx skeletal muscle function. Muscle Nerve 32, $751-760$.

Baudry, C., 1982. The antianginal effect of molsidomine in prolonged oral therapy. A double blind, crossover, randomized study. Acta Cardiol. 37, 23-30.

Bogdan, C., 2001. Nitric oxide and the immune response. Nat. Immunol. 2, 907-916.

Bosurgi, L., Corna, G., Vezzoli, M., Touvier, T., Cossu, G., Manfredi, A.A., Brunelli, S. Rovere-Querini, P., 2012. Transplanted mesoangioblasts require macrophage IL-10 for survival in a mouse model of muscle injury. J. Immunol 188 $6267-6277$

Brenman, J.E., Chao, D.S., Xia, H., Aldape, K., Bredt, D.S., 1995. Nitric oxide synthase complexed with dystrophin and absent from skeletal muscle sarcolemma in Duchenne muscular dystrophy. Cell 82, 743-752.

Brunelli, S., Rovere-Querini, P., 2008. The immune system and the repair of skeletal muscle. Pharmacol. Res. 58, 117-121.

Brunelli, S., Sciorati, C., D'Antona, G., Innocenzi, A., Covarello, D., Galvez, B.G., Perrotta, C., Monopoli, A., Sanvito, F., Bottinelli, R., Ongini, E., Cossu, G., Clementi, E., 2007. Nitric oxide release combined with nonsteroidal antiinflammatory activity prevents muscular dystrophy pathology and enhances stem cell therapy. Proc. Natl. Acad. Sci. USA 104, 264-269.

Buono, R., Vantaggiato, C., Pisa, V., Azzoni, E., Bassi, M.T., Brunelli, S., Sciorati, C. Clementi, E., 2012. Nitric oxide sustains long-term skeletal muscle regeneration by regulating fate of satellite cells via signaling pathways requiring Vangl2 and cyclic GMP. Stem Cells 30, 197-209.

Chang, W.J., Iannaccone, S.T., Lau, K.S., Masters, B.S., McCabe, T.J., McMillan, K. Padre, R.C., Spencer, M.J., Tidball, J.G., Stull, J.T., 1996. Neuronal nitric oxide synthase and dystrophin-deficient muscular dystrophy. Proc. Natl. Acad. Sci. USA 93, 9142-9147.

Coletti, D., Moresi, V., Adamo, S., Molinaro, M., Sassoon, D., 2005. Tumor necrosis factor-alpha gene transfer induces cachexia and inhibits muscle regeneration. Genesis 43, 120-128.

Corna, G., Campana, L., Pignatti, E., Castiglioni, A., Tagliafico, E., Bosurgi, L., Campanella, A., Brunelli, S., Manfredi, A.A., Apostoli, P., Silvestri, L., Camaschella, C. Rovere-Querini, P., 2010. Polarization dictates iron handling by inflammatory and alternatively activated macrophages. Haematologica 95, 1814-1822.

Crisafulli, C., Galuppo, M., Cuzzocrea, S., 2009. Effects of genetic and pharmacological inhibition of TNF-alpha in the regulation of inflammation in macrophages. Pharmacol. Res. 60, 332-340.

De Palma, C., Clementi, E., 2012. Nitric oxide in myogenesis and therapeutic muscle repair. Mol. Neurobiol. 46, 682-692.

Dendorfer, A., 1996. [Pharmacology of nitrates and other NO donors]. Herz 21 (Suppl. 1), 38-49.

Duclos, F., Straub, V., Moore, S.A., Venzke, D.P., Hrstka, R.F., Crosbie, R.H., Durbeej, M. Lebakken, C.S., Ettinger, A.J., van der Meulen, J., Holt, K.H., Lim, L.E., Sanes, J.R., Davidson, B.L., Faulkner, J.A., Williamson, R., Campbell, K.P., 1998. Progressive muscular dystrophy in alpha-sarcoglycan-deficient mice. J. Cell Biol. 142, $1461-1471$.

Emery, A.E., 2002. The muscular dystrophies. Lancet 359, 687-695.

Filippin, L.I., Moreira, A.J., Marroni, N.P., Xavier, R.M., 2009. Nitric oxide and repair of skeletal muscle injury. Nitric Oxide.

Fung, H.L., 1993. Clinical pharmacology of organic nitrates. Am. J. Cardiol. 72, 9C-13C; discussion 14C-15C

Galvez, B.G., Sampaolesi, M., Brunelli, S., Covarello, D., Gavina, M., Rossi, B., Constantin, G., Costantin, G., Torrente, Y., Cossu, G., 2006. Complete repair of dystrophic skeletal muscle by mesoangioblasts with enhanced migration ability. J. Cell Biol. 174, 231-243.

Gordon, S., Martinez, F.O., 2010. Alternative activation of macrophages: mechanism and functions. Immunity 32, 593-604.

Hickey, M.J., 2001. Role of inducible nitric oxide synthase in the regulation of leucocyte recruitment. Clin. Sci. 100, 1-12.

Hnia, K., Gayraud, J., Hugon, G., Ramonatxo, M., De La Porte, S., Matecki, S., Mornet, D., 2008. L-arginine decreases inflammation and modulates the nuclear factorkappaB/matrix metalloproteinase cascade in mdx muscle fibers. Am. J. Pathol. 172, 1509-1519.

Hodgetts, S., Radley, H., Davies, M., Grounds, M.D., 2006. Reduced necrosis of dystrophic muscle by depletion of host neutrophils, or blocking TNFalpha function with Etanercept in mdx mice. Neuromuscular Disord. 16, 591-602.

Lesault, P.F., Theret, M., Magnan, M., Cuvellier, S., Niu, Y., Gherardi, R.K., Tremblay, J.P., Hittinger, L., Chazaud, B., 2012. Macrophages improve survival, proliferation and migration of engrafted myogenic precursor cells into mdx skeletal muscle. PloS One 7, e46698.

Mantovani, A., Biswas, S.K., Galdiero, M.R., Sica, A., Locati, M., 2013. Macrophage plasticity and polarization in tissue repair and remodeling. J. Pathol. 229, 176-185.

Marques, M.J., Luz, M.A., Minatel, E., Neto, H.S., 2005. Muscle regeneration in dystrophic mdx mice is enhanced by isosorbide dinitrate. Neurosci. Lett. 382, 342-345.

Martinez, F.O., Gordon, S., Locati, M., Mantovani, A., 2006. Transcriptional profiling of the human monocyte-to-macrophage differentiation and polarization: new molecules and patterns of gene expression. J. Immunol. 177, 7303-7311.

McCafferty, D.M., Mudgett, J.S., Swain, M.G., Kubes, P., 1997. Inducible nitric oxide synthase plays a critical role in resolving intestinal inflammation. Gastroenterology 112, 1022-1027.

Messin, R., Bruhwyler, J., Dubois, C., Famaey, J.P., Geczy, J., 2006. Tolerability to 1 -year treatment with once-daily molsidomine in patients with stable angina. Adv, Ther. 23, 601-614.

Mosser, D.M., Edwards, J.P., 2008. Exploring the full spectrum of macrophage activation. Nat. Rev. Immunol. 8, 958-969.

Nagy, G., Clark, J.M., Buzas, E.I., Gorman, C.L., Cope, A.P., 2007. Nitric oxide, chronic inflammation and autoimmunity. Immunol. Lett. 111, 1-5.

Nguyen, H.X., Tidball, J.G., 2003. Expression of a muscle-specific, nitric oxide synthase transgene prevents muscle membrane injury and reduces muscle inflammation during modified muscle use in mice. J. Physiol. 550, 347-356.

Noack, E., Feelisch, M., 1989. Molecular aspects underlying the vasodilator action of molsidomine. J. Cardiovasc. Pharmacol. 14 (Suppl. 11), S1-S5.

Rigamonti, E., Touvier, T., Clementi, E., Manfredi, A.A., Brunelli, S., Rovere-Querini, P., 2013. Requirement of inducible nitric oxide synthase for skeletal muscle regeneration after acute damage. J. Immunol. 190, 1767-1777.

Sciorati, C. Buono, R., Azzoni, E. Casati, S., Ciuffreda, P., D'Angelo, G., Cattaneo, D., Brunelli, S., Clementi, E., 2010. Co-administration of ibuprofen and nitric oxide is an effective experimental therapy for muscular dystrophy, with immediate applicability to humans. Br. J. Pharmacol. 160, 1550-1560.

Sciorati, C., Miglietta, D., Buono, R., Pisa, V., Cattaneo, D., Azzoni, E., Brunelli, S., Clementi, E., 2011. A dual acting compound releasing nitric oxide (NO) and ibuprofen, NCX 320, shows significant therapeutic effects in a mouse model of muscular dystrophy. Pharmacol. Res. 64, 210-217.

Sciorati, C., Touvier, T., Buono, R., Pessina, P., François, S., Perrotta, C., Meneveri, R., Clementi, E., Brunelli, S., 2009. Necdin is expressed in cachectic skeletal muscle to protect fibers from tumor-induced wasting. J. Cell Sci. 122, 1119-1125.

Tidball, J.G., 2005. Inflammatory processes in muscle injury and repair. Am. J. Physiol. Regul. Integr. Comp. Physiol. 288, R345-R353.

Tidball, J.G., Villalta, S.A., 2010. Regulatory interactions between muscle and the immune system during muscle regeneration. Am. J. Physiol. Regul. Integr. Comp. Physiol. 298, R1173-R1187.

Tripathi, P., Kashyap, L., Singh, V., 2007. The role of nitric oxide in inflammatory reactions. FEMS Immunol. Med. Microbiol. 51, 443-452.

Villalta, S.A., Deng, B., Rinaldi, C., Wehling-Henricks, M., Tidball, J.G., 2011a. IFNgamma promotes muscle damage in the mdx mouse model of Duchenne muscular dystrophy by suppressing M2 macrophage activation and inhibiting muscle cell proliferation. J. Immunol. 187, 5419-5428.

Villalta, S.A., Rinaldi, C., Deng, B., Liu, G., Fedor, B., Tidball, J.G., 2011b. Interleukin-10 reduces the pathology of mdx muscular dystrophy by deactivating M1 macrophages and modulating macrophage phenotype. Hum. Mol. Genet. 20, 790-805.

Voisin, V., Sebrie, C., Matecki, S., Yu, H., Gillet, B., Ramonatxo, M., Israel, M., De la Porte, S., 2005. L-arginine improves dystrophic phenotype in mdx mice. Neurobiol. Dis. 20, 123-130.

Wahl, S.M., McCartney-Francis, N., Chan, J., Dionne, R., Ta, L., Orenstein, J.M., 2003. Nitric oxide in experimental joint inflammation. Benefit or detriment? Cells Tissues Organs 174, 26-33.

Wang, G., Burczynski, F.J., Hasinoff, B.B., Zhang, K., Lu, Q., Anderson, J.E., 2009. Development of a nitric oxide-releasing analogue of the muscle relaxant guaifenesin for skeletal muscle satellite cell myogenesis. Mol. Pharm. 6, 895-904. Wehling, M., Spencer, M.J., Tidball, J.G., 2001. A nitric oxide synthase transgene ameliorates muscular dystrophy in mdx mice. J. Cell Biol. 155, 123-131.

Wehling-Henricks, M., Tidball, J.G., 2011. Neuronal nitric oxide synthase-rescue of dystrophin/utrophin double knockout mice does not require nNOS localization to the cell membrane. PloS One 6, e25071. 